\title{
Clinical outcomes in patients with ST-segment elevation myocardial infarction treated with everolimus-eluting stents versus bare-metal stents (EXAMINATION): 5-year results of a randomised trial
}

Manel Sabaté, Salvatore Brugaletta, Angel Cequier, Andrés Iñiguez, Antonio Serra, Pilar Jiménez-Quevedo, Vicente Mainar, Gianluca Campo, Maurizio Tespili, Peter den Heijer, Armando Bethencourt, Nicolás Vazquez, Gerrit Anne van Es, Bianca Backx, Marco Valgimigli, Patrick W Serruys

\begin{abstract}
Summary
Background Data for the safety and efficacy of new-generation drug-eluting stents at long-term follow-up, and specifically in patients with ST-segment elevation myocardial infarction, are scarce. In the EXAMINATION trial, we compared everolimus-eluting stents (EES) with bare-metal stents (BMS) in an all-comer population with ST-segment elevation myocardial infarction. In this study, we assessed the 5-year outcomes of the population in the EXAMINATION trial.
\end{abstract}

Methods In the multicentre EXAMINATION trial, done in Italy, Spain, and the Netherlands, patients with ST-segment elevation myocardial infarction were randomly assigned in a 1:1 ratio to receive EES or BMS. The random allocation schedule was computer-generated and central randomisation (by telephone) was used to allocate patients in blocks of four or six, stratified by centre. Patients were masked to treatment assignment. At 5 years, we assessed the combined patient-oriented outcome of all-cause death, any myocardial infarction, or any revascularisation. Analysis was by intention to treat. This trial is registered with ClinicalTrials.gov, number NCT00828087.

Findings 1498 patients were randomly assigned to receive either EES $(n=751)$ or BMS $(n=747)$. At 5 years, complete clinical follow-up data were obtained for 731 patients treated with EES and 727 treated with BMS $(97 \%$ of both groups). The patient-oriented endpoint occurred in $159(21 \%)$ patients in the EES group versus $192(26 \%)$ in the BMS group (hazard ratio $0 \cdot 80,95 \% \mathrm{CI} 0 \cdot 65-0 \cdot 98 ; \mathrm{p}=0 \cdot 033$ ). This difference was mainly driven by a reduced rate of all-cause mortality (65 [9\%] vs $88[12 \%] ; 0 \cdot 72,0 \cdot 52-0 \cdot 10 ; \mathrm{p}=0 \cdot 047)$.

Interpretation Our findings should be taken as a point of reference for the assessment of new bioresorbable polymer-based metallic stents or bioresorbable scaffolds in patients with ST-segment elevation myocardial infarction.

Funding Spanish Heart Foundation.

\section{Introduction}

Percutaneous coronary intervention (PCI) is the standard of treatment for patients with ST-elevation myocardial infarction when done at specialist centres within the time from onset of symptoms as per guidelines. ${ }^{1}$ ST-elevation myocardial infarction represents both a model of a thrombotic setting and a challenging clinical scenario to test new intracoronary devices. ${ }^{2}$ In this clinical setting, first-generation drug-eluting stents (DES) reduced clinical and angiographic restenosis, compared with bare-metal stents (BMS). ${ }^{3-7}$ Conversely, these benefits were counterbalanced by an increased risk of very late stent thrombosis, ${ }^{8-11}$ safety concerns that were confirmed on autopsy, and intravascular imaging studies showing evidence of incomplete endothelialisation, delayed arterial healing, and vessel remodelling because of chronic inflammation. ${ }^{12-15}$ The development of neotherosclerosis, ${ }^{16}$ which might occur earlier after DES than after BMS ${ }^{17}$ has also been identified as a potential cause.

Compared with BMS and first-generation DES, the Xience V stent (Abbott Vascular, Santa Clara, CA, USA) reduced rates of cardiovascular events in randomised controlled trials and meta-analysis at short-term and mid-term follow-up. ${ }^{18,19}$ The 2014 myocardial revascularisation guidelines recommend the use of second-generation DES for ST-elevation myocardial infarction. ${ }^{1}$ However, long-term follow-up data are lacking.

The EXAMINATION (clinical Evaluation of the Xience-V stent in Acute Myocardial INfArcTION) allcomers trial was designed to compare clinical outcomes in patients with ST-elevation myocardial infarction receiving EES with those receiving BMS. ${ }^{20}$ At a maximum follow-up of 2 years, the use of EES was associated with a reduced rate of repeat revascularisation and stent thrombosis, although it did not reduce the combined patient-oriented primary endpoint. ${ }^{21,22}$ In this study, we compared 5-year clinical outcomes in patients with STelevation myocardial infarction treated with EES versus $\mathrm{BMS}$ in the EXAMINATION trial, ${ }^{20}$ focusing on differences between the first and subsequent years of follow-up.
Lancet 2016; 387: 357-66 Published Online October 29, 2015 http://dx.doi.org/10.1016 S0140-6736(15)00548-6 See Comment page 316

University Hospital Clínic Institut d'Investigacions Biomèdiques August Pi i Sunyer (IDIBAPS), Barcelona, Spain (M Sabaté MD, S Brugaletta MD); University Hospital of Bellvitge, Barcelona, Spain (A Cequier MD); Hospital do Meixoeiro, Vigo, Spain

(A Iñiguez MD); University Hospital of Sant Pau, Barcelona, Spain (A Serra MD); University Hospital San Carlos, Madrid, Spain (PJiménez-Quevedo MD) Hospital General of Alicante, Alicante, Spain (V Mainar MD); University Hospital Ferrara, Ferrara, Italy (G Campo MD); University Hospital Bolognini Seriate, Bergamo, Italy (M Tespili MD); Amphia Ziekenhuis, Breda, Netherlands (P den Heijer MD); Hospital Son Espases, Palma de Mallorca, Spain (A Bethencourt MD); Hospital Juan Canalejo, A Coruña, Spain (N Vazquez MD); Cardialysis, Rotterdam, Netherlands (G A van Es PhD, B Backx RN) Erasmus MC, Rotterdam, Netherlands (M Valgimigli MD); University Hospital of Bern, Inselhospital, Bern, Switzerland (M Valgimigli); and International Centre of Circulatory Health, Imperial College London, London, UK (Prof PW Serruys MD)

Correspondence to: Dr Manel Sabaté, Cardiology Department, Hospital Clinic, University of Barcelona, c/Villarroel 170, 08036 Barcelona, Spain masabate@clinic.ub.es 
Research in context

\section{Systematic review}

We searched PubMed from Jan 10, 2005, to Aug 10, 2015, for complete reports of trials in which drug-eluting stents (DES) were compared with bare-metal stents (BMS) in patients with ST-elevation myocardial infarction. We found several trials comparing first-generation DES versus BMS in this specific clinical setting. By narrowing our search to second-generation DES, we identified the COMFORTABLE-AMI trial of the comparison of biolimus-eluting stent with BMS and the XAMI trial of the comparison of everolimus-eluting stent (EES) versus first-generation DES. Follow-up of these studies was 2 years and 1 year. Additionally, we identified other trials in an all-comer population including ST-elevation myocardial infarction (RESOLUTE AC, LEADERS, and COMPARE trials) of the comparison of two different second-generation DES or second-generation versus first-generation DES
Added value of this study

Our study is the first report of a randomised comparison of a second-generation DES and BMS in the clinical setting of ST-elevation myocardial infarction with long-term follow-up (up to 5 years). At 5 years, patients allocated to EES had a reduction in both the combined patient-oriented and device-oriented endpoints mainly driven by a reduction in all-cause mortality and revascularisation. Additionally, these results were obtained in the absence of very late hazards (namely stent thrombosis, target vessel myocardial infarction, or restenosis)

Interpretation of all the available evidence

The benefit of EES in ST-elevation myocardial infarction at long term is reassuring and confirms the use of secondgeneration stents as the current gold standard treatment in this clinical context.

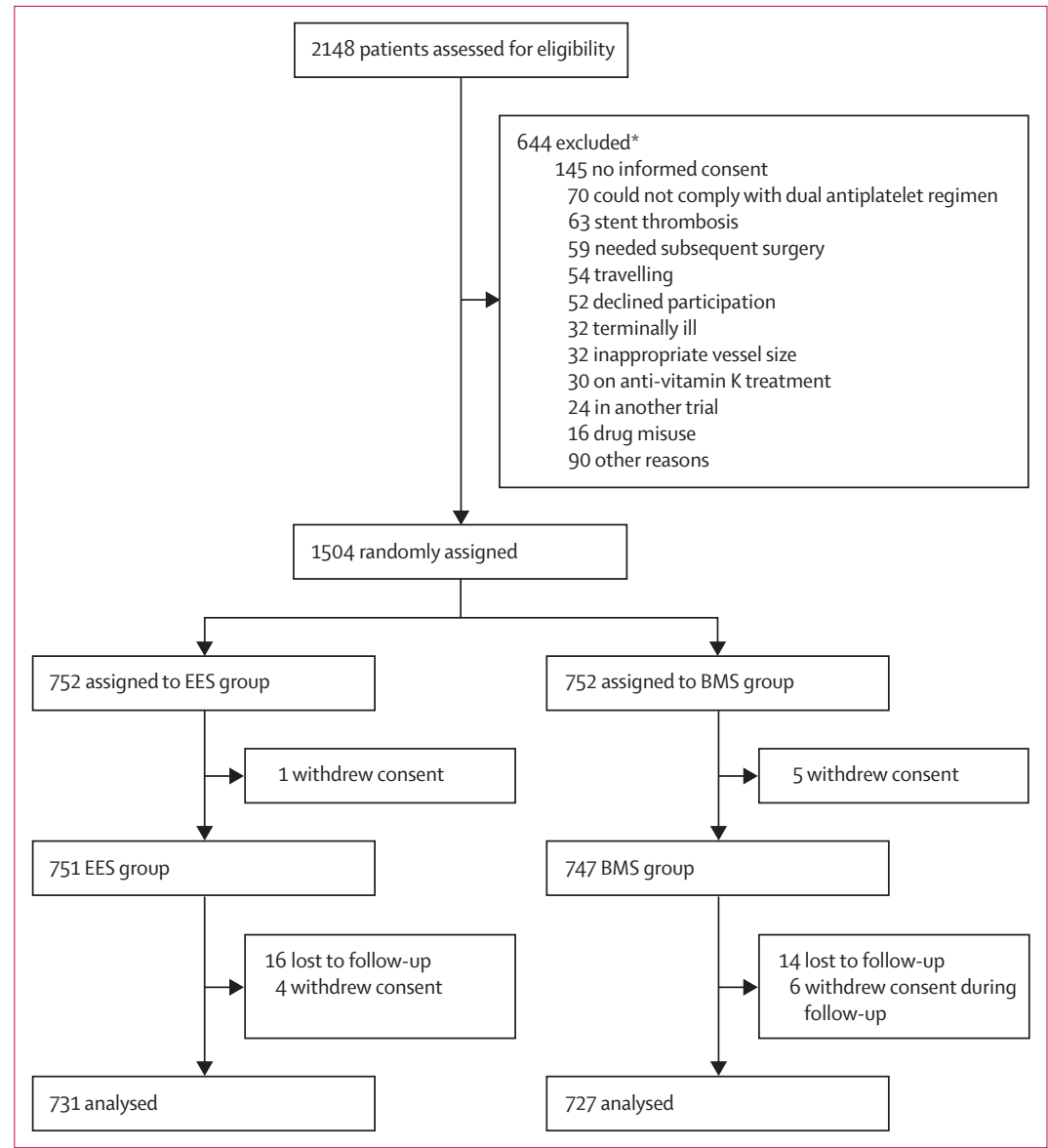

Figure 1: Trial profile

$\mathrm{EES}=$ everolimus-eluting stents. BMS=bare-metal stents. *Some patients had more than one reason for exclusion.

\section{Methods}

\section{Study design and participants}

The EXAMINATION study was a multicentre, multinational, prospective, randomised, two-arm, singleblind, controlled trial in patients with ST-elevation myocardial infarction; the detailed study design has been previously reported. ${ }^{20}$ Briefly, the study had broad inclusion and few exclusion criteria to ensure an allcomers population with ST-elevation myocardial infarction, representative of routine clinical practice. The inclusion criteria were any adult presenting with STelevation myocardial infarction and meeting the following electrocardiograph (ECG) criteria: at least $1 \mathrm{~mm}$ in two or more standard leads, at least $2 \mathrm{~mm}$ in two or more contiguous precordial leads, or new left bundle-branch block within the first $48 \mathrm{~h}$ after onset of symptoms that required emergency $\mathrm{PCI}$, and a vessel size of 2.25-4.00 $\mathrm{mm}$ without other anatomical restrictions. Exclusion criteria were age younger than 18 years, pregnancy, chronic treatment with anti-vitamin K agents, ST-elevation myocardial infarction secondary to stent thrombosis, and known intolerance to aspirin, clopidogrel, heparin, stainless steel, everolimus, or contrast material.

12 centres in Italy, Spain, and the Netherlands participated in the trial. All centres received the approval of their medical ethics committee for the protocol and for the acquisition of informed consent. The study complied with the Declaration of Helsinki and applicable local requirements. All patients provided written informed consent for participation in the trial.

\section{Randomisation and masking}

All recruited patients were randomly allocated in a 1:1 ratio to the EES (Xience V stent) or cobalt-chromium BMS (Multilink Vision stent, Abbott Vascular, Santa Clara, CA) groups. The allocation sequence with 
block sizes of four or six was computer-generated. Central randomisation (by telephone) was stratified by centre. Patients were masked to treatment assignment.

\section{Procedures}

Both EES and BMS have the same design. At the index procedure, anticoagulation was achieved with either unfractionated heparin or bivalirudin. The use of glycoprotein IIb/IIIa inhibitors was at the discretion of the operator. Administration of aspirin (loading dose 250-500 mg) and clopidogrel (loading dose $\geq 300 \mathrm{mg}$ ) was required before PCI for patients not on chronic antiplatelet treatment (neither prasugrel nor ticagrelor had become available at the time of recruitment). Clopidogrel (75 mg/day) was prescribed for at least 1 year and aspirin (100 mg/day) indefinitely. Manual thrombectomy followed by direct stenting was the recommended technique during PCI, although other devices could also be used if thought to be necessary. Operators were instructed to use only the randomly assigned stent type for the index procedure.

\section{Outcomes}

Primary and secondary endpoints of the study have been reported elsewhere. ${ }^{21}$ Briefly, the primary endpoint was the patient-oriented combined endpoint of all-cause death, any myocardial infarction, or any revascularisation at 1 year as per the definition by the Academic Research Consortium (ARC) definition. ${ }^{23}$ The main secondary endpoints were the device-oriented combined endpoint of cardiac death, target vessel myocardial infarction, or target lesion revascularisation; ${ }^{23}$ all-cause and cardiac death; any myocardial infarction (WHO extended definition ${ }^{24}$ ); target lesion revascularisation; target vessel revascularisation; and stent thrombosis (as per ARC definitions ${ }^{23}$ ). All the above endpoints had been assessed up to the 5-year follow-up. Detailed definitions of the endpoints have been reported elsewhere. ${ }^{20}$ Patients with multivessel disease needing staged PCI could also be included. Staged procedures had to be done within the first month after discharge and with the same stent as per randomisation.

Follow-up included a clinical visit or telephone contact at 30 days, 6 months, and 1 year, and then yearly contact for up to 5 years. No angiographic follow-up was mandated in the protocol.

Independent study monitors verified all case reports from data on site. Data were stored in a central database, which was maintained by a contract research organisation (Cardialysis, Rotterdam, Netherlands). A clinical event committee, whose members were masked to the assigned stent, independently adjudicated all deaths, potential myocardial infarctions, stent thrombosis, and revascularisation procedures.

\section{Statistical analysis}

The trial was powered for superiority of the primary endpoint at 1 year. $^{20,21}$ The sample size calculation was based on a two-sided type I error rate $\alpha$ of $0 \cdot 05$, EES to
BMS randomisation ratio of $1: 1$, and a statistical power of at least $86 \%$ to detect a $30 \%$ reduction in the rate of the primary endpoint at 1 year (ie, to an approximate event rate of $20.5 \%$ in the control group and $14.5 \%$ in the EES group). For the purpose of this analysis, we calculated two-sided 95\% CI and two-sided $\mathrm{p}$ values for

\begin{tabular}{|c|c|c|c|c|}
\hline & $\begin{array}{l}\text { EES group } \\
(n=751)\end{array}$ & $\begin{array}{l}\text { BMS group } \\
(n=747)\end{array}$ & Hazard ratio $(95 \% \mathrm{Cl})$ & p value \\
\hline \multicolumn{5}{|l|}{ 1-year follow-up } \\
\hline Primary endpoint, patient oriented ${ }^{*}$ & $89(12 \%)$ & $106(14 \%)$ & $0.83(0.62-1.09)$ & 0.19 \\
\hline Device-oriented endpoint $†$ & $44(6 \%)$ & $63(8 \%)$ & $0.69(0.48-0.10)$ & 0.0568 \\
\hline Death $\neq$ & $26(3 \%)$ & $26(3 \%)$ & $0.99(0.58-1.71)$ & 1.00 \\
\hline Cardiac & $24(3 \%)$ & $21(3 \%)$ & $0.67(0.32-2.04)$ & 0.76 \\
\hline Vascular & $1(<1 \%)$ & $3(<1 \%)$ & $0.33(0.03-3 \cdot 19)$ & 0.37 \\
\hline Non-cardiovascular & $1(<1 \%)$ & $2(<1 \%)$ & $0.50(0.05-5.48)$ & 0.62 \\
\hline Myocardial infarction $\S$ & $10(1 \%)$ & $15(2 \%)$ & $0.60(0.22-1.64)$ & 0.32 \\
\hline Target vessel related & $8(1 \%)$ & $15(2 \%)$ & $0.44(0.14-1.43)$ & 0.14 \\
\hline Non-target vessel related & $2(<1)$ & $0(0 \%)$ & $1.99(0.18-21 \cdot 95)$ & 0.49 \\
\hline Revascularisation & $60(8 \%)$ & $79(11 \%)$ & $0.75(0.54-1.05)$ & 0.09 \\
\hline Target lesion & $16(2 \%)$ & $37(5 \%)$ & $0.42(0.24-0.76)$ & 0.0032 \\
\hline Target vessel & $28(4 \%)$ & $51(7 \%)$ & $0.54(0.34-0.85)$ & 0.0077 \\
\hline Non-target vessel & $40(5 \%)$ & $41(5 \%)$ & $1.00(0.64-1.52)$ & 0.90 \\
\hline Definite stent thrombosis $\mathbb{I}$ & $4(1 \%)$ & $14(2 \%)$ & $0.28(0.09-0.86)$ & 0.0183 \\
\hline $\begin{array}{l}\text { Definite or probable stent } \\
\text { thrombosis } \boldsymbol{T}\end{array}$ & $7(1 \%)$ & $19(3 \%)$ & $0.36(0.15-0.87)$ & 0.022 \\
\hline \multicolumn{5}{|l|}{ 2-year follow-up } \\
\hline Patient-oriented endpoint $¥$ & $108(14 \%)$ & $129(17 \%)$ & $0.81(0.63-1.05)$ & 0.11 \\
\hline Device-oriented endpoint $†$ & $61(8 \%)$ & $82(11 \%)$ & $0.72(0.52-1.01)$ & 0.055 \\
\hline Death $\S$ & $32(4 \%)$ & $37(5 \%)$ & $0.86(0.54-1 \cdot 38)$ & 0.52 \\
\hline Cardiac & $28(4 \%)$ & $28(4 \%)$ & $0.99(0.59-1.68)$ & $1 \cdot 0$ \\
\hline Vascular & $3(<1 \%)$ & $3(<1 \%)$ & $0.99(0.20-4.92)$ & 0.99 \\
\hline Non-cardiovascular & $1(<1 \%)$ & $6(<1 \%)$ & $0.17(0.02-1.37)$ & $0 \cdot 10$ \\
\hline Myocardial infarction* & $14(2 \%)$ & $18(2 \%)$ & $0.77(0 \cdot 38-1 \cdot 55)$ & 0.45 \\
\hline Target vessel related & $11(1 \%)$ & $16(2 \%)$ & $0.68(0.32-1.47)$ & 0.46 \\
\hline Non-target vessel related & $3(<1 \%)$ & $3(<1 \%)$ & $1.00(0.20-4.93)$ & 0.99 \\
\hline Revascularisation & $73(10 \%)$ & $95(13 \%)$ & $0.75(0.55-1.01)$ & 0.05 \\
\hline Target lesion & $22(3 \%)$ & $42(6 \%)$ & $0.51(0.31-0.86)$ & 0.01 \\
\hline Target vessel & $36(5 \%)$ & $59(8 \%)$ & $0.59(0.39-0.90)$ & 0.009 \\
\hline Non-target vessel & $46(6 \%)$ & $52(7 \%)$ & $0.87(0.59-1 \cdot 30)$ & 0.51 \\
\hline Definite stent thrombosis $\mathbb{\Psi}$ & $6(1 \%)$ & $16(2 \%)$ & $0.37(0.15-0.95)$ & 0.03 \\
\hline $\begin{array}{l}\text { Definite or probable stent } \\
\text { thrombosis } \boldsymbol{T}\end{array}$ & $10(1 \%)$ & $21(3 \%)$ & $0.47(0.22-1 \cdot 00)$ & 0.04 \\
\hline \multicolumn{5}{|l|}{ 3-year follow-up } \\
\hline Patient-oriented $\ddagger$ & $116(15 \%)$ & $151(20 \%)$ & $0.75(0.59-0.95)$ & 0.017 \\
\hline Device-oriented endpoint $\dagger$ & $66(9 \%)$ & $97(13 \%)$ & $0.66(0.48-0.90)$ & 0.010 \\
\hline Death $\$$ & $36(5 \%)$ & $55(7 \%)$ & $0.65(0.43-0.99)$ & 0.043 \\
\hline Cardiac & $30(4 \%)$ & $39(5 \%)$ & $0.76(0.48-1.23)$ & $0 \cdot 27$ \\
\hline Vascular & $3(<1 \%)$ & $3(<1 \%)$ & $0.99(0.20-4.92)$ & 0.99 \\
\hline Non-cardiovascular & $6(1 \%)$ & $20(3 \%)$ & $0.23(0.07-0.80)$ & 0.021 \\
\hline Myocardial infarction* & $14(2 \%)$ & $13(2 \%)$ & $1.07(0.50-2.27)$ & 0.86 \\
\hline Target vessel related & $10(1 \%)$ & $11(1 \%)$ & $0.90(0.38-2 \cdot 12)$ & 0.81 \\
\hline Non-target vessel related & $5(<1 \%)$ & $3(<1 \%)$ & $1.66(0.40-6.94)$ & 0.49 \\
\hline \multirow[t]{2}{*}{ Revascularisation } & $77(10 \%)$ & $102(14 \%)$ & $0.73(0.55-0.99)$ & 0.040 \\
\hline & & & \multicolumn{2}{|c|}{ (Table continues on next page) } \\
\hline
\end{tabular}




\begin{tabular}{|c|c|c|c|c|}
\hline & $\begin{array}{l}\text { EES group } \\
(n=751)\end{array}$ & $\begin{array}{l}\text { BMS group } \\
(n=747)\end{array}$ & Hazard ratio $(95 \% \mathrm{Cl})$ & p value \\
\hline \multicolumn{5}{|c|}{ (Continued from previous page) } \\
\hline Target lesion & $24(3 \%)$ & $47(6 \%)$ & $0.50(0.31-0.82)$ & 0.006 \\
\hline Target vessel & $40(5 \%)$ & $66(9 \%)$ & $0.59(0.40-0.87)$ & 0.008 \\
\hline Non-target vessel & $51(7 \%)$ & $56(7 \%)$ & $0.90(0.62-1.32)$ & 0.59 \\
\hline Definite stent thrombosis $\boldsymbol{\Psi}$ & $8(1 \%)$ & $16(2 \%)$ & $0.49(0.21-1.15)$ & 0.10 \\
\hline 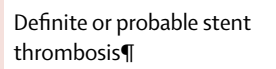 & $11(1 \%)$ & $21(3 \%)$ & $0.52(0.25-1.07)$ & 0.08 \\
\hline \multicolumn{5}{|l|}{ 4-year follow-up } \\
\hline Patient-oriented $¥$ & $134(18 \%)$ & $166(22 \%)$ & $0.78(0.62-0.98)$ & 0.033 \\
\hline Device-oriented endpoint ${ }^{\dagger}$ & $76(10 \%)$ & $106(14 \%)$ & $0.70(0.52-0.93)$ & 0.016 \\
\hline Deaths & $46(6 \%)$ & $67(9 \%)$ & $0.68(0.47-0.99)$ & 0.042 \\
\hline Cardiac & $36(5 \%)$ & $43(6 \%)$ & $0.83(0.53-1.29)$ & 0.41 \\
\hline Vascular & $3(<1 \%)$ & $4(1 \%)$ & $0.75(0.17-3.33)$ & 0.70 \\
\hline Non-cardiovascular & $10(1 \%)$ & $28(4 \%)$ & $0.35(0.15-0.82)$ & 0.015 \\
\hline Myocardial infarction* & $20(3 \%)$ & $16(2 \%)$ & $1.24(0.64-2.40)$ & 0.52 \\
\hline Target vessel related & $13(2 \%)$ & $13(2 \%)$ & $0.99(0.46-2.14)$ & 0.98 \\
\hline Non-target vessel related & $8(1 \%)$ & $4(1 \%)$ & $1.99(0.60-6.62)$ & 0.26 \\
\hline Revascularisation & $86(11 \%)$ & $110(15 \%)$ & $0.76(0.57-1.01)$ & 0.055 \\
\hline Target lesion & $28(4 \%)$ & $52(7 \%)$ & $0.53(0.33-0.83)$ & 0.006 \\
\hline Target vessel & $44(6 \%)$ & $72(10 \%)$ & $0.59(0.41-0.86)$ & 0.006 \\
\hline Non-target vessel & $58(8 \%)$ & $60(8 \%)$ & $0.96(0.67-1.37)$ & 0.80 \\
\hline Definite stent thrombosis $\boldsymbol{q}$ & $11(1 \%)$ & $17(2 \%)$ & $0.64(0.30-1.64)$ & 0.25 \\
\hline $\begin{array}{l}\text { Definite or probable stent } \\
\text { thrombosis } \boldsymbol{T}\end{array}$ & $14(2 \%)$ & $22(3 \%)$ & $0.63(0.32-1.23)$ & 0.17 \\
\hline \multicolumn{5}{|l|}{ 5-year follow-up } \\
\hline Patient-oriented endpoint $\neq$ & $159(21 \%)$ & $192(26 \%)$ & $0.80(0.65-0.98)$ & 0.033 \\
\hline Device-oriented endpoint ${ }^{\dagger}$ & $88(12 \%)$ & $113(15 \%)$ & $0.75(0.57-0.99)$ & 0.043 \\
\hline Deaths & $65(9 \%)$ & $88(12 \%)$ & $0.72(0.52-1.00)$ & 0.047 \\
\hline Cardiac & $47(6 \%)$ & $55(7 \%)$ & $0.84(0.57-1.24)$ & 0.37 \\
\hline Vascular & $4(1 \%)$ & $5(1 \%)$ & $0.79(0.21-2.92)$ & 0.72 \\
\hline Non-cardiovascular & $14(2 \%)$ & $28(4 \%)$ & $0.49(0.26-0.92)$ & 0.027 \\
\hline Myocardial infarction* & $35(5 \%)$ & $27(4 \%)$ & $1.27(0.77-2 \cdot 10)$ & 0.35 \\
\hline Target vessel related & $21(3 \%)$ & $23(3 \%)$ & $0.90(0.50-1.62)$ & 0.71 \\
\hline Non-target vessel related & $15(2 \%)$ & $6(1 \%)$ & $2.44(0.95-6.29)$ & 0.07 \\
\hline Revascularisation & $93(12 \%)$ & $116(16 \%)$ & $0.77(0.59-1.01)$ & 0.06 \\
\hline Target lesion & $32(4 \%)$ & $54(7 \%)$ & $0.57(0.37-0.89)$ & 0.012 \\
\hline Target vessel & $49(7 \%)$ & $76(10 \%)$ & $0.62(0.43-0.89)$ & 0.009 \\
\hline Non-target vessel & $62(8 \%)$ & $62(8 \%)$ & $0.98(0.69-1.39)$ & 0.91 \\
\hline Definite stent thrombosis $\boldsymbol{q}$ & $12(2 \%)$ & $18(2 \%)$ & $0.65(0.31-1 \cdot 36)$ & 0.25 \\
\hline $\begin{array}{l}\text { Definite or probable stent } \\
\text { thrombosis } \boldsymbol{T}\end{array}$ & $15(2 \%)$ & $23(3 \%)$ & $0.64(0.33-1.23)$ & 0.18 \\
\hline \multicolumn{5}{|c|}{$\begin{array}{l}\text { Data are number (\%), unless otherwise indicated. EES=everolimus-eluting stent. BMS=bare metal stent. } \\
\text { ARC=Academic Research Consortium. }{ }^{*} \text { Myocardial infarction was adjudicated in accordance with WHO's extended } \\
\text { definition. }{ }^{24}+\text { Combined (hierarchical) endpoint of cardiac death, target vessel myocardial infarction, and target lesion } \\
\text { revascularisation }{ }^{23} \neq \text { Combined (hierarchical) endpoint of all-cause death, any recurrent myocardial infarction, and an) } \\
\text { revascularisation. }{ }^{23} \text { SDeath was adjudicated in accordance with the ARC's recommendations. }{ }^{23} \text { qStent thrombosis was } \\
\text { defined in accordance with ARC's recommendations. }{ }^{23}\end{array}$} \\
\hline
\end{tabular}

See Online for appendix superiority for all endpoints to allow conventional interpretation of results.

Continuous variables are presented as mean and SD, and categorical data are presented as counts and percentages. All analyses were by intention to treat; patients who were lost to follow-up were censored at their last known contact. We used the Mantel-Cox method to calculate rate ratios (RR), 95\% CI for comparisons of clinical outcomes between groups, and the log-rank test to calculate corresponding p values. We constructed survival curves for time-to-event variables using Kaplan-Meier estimates. Landmark analyses were done from 0 to 1 year and from 1 year to 5 years of follow-up to assess the effect of time on the occurrence of events.

Subgroup analyses were the following prespecified variables: sex, age greater than 75 years, presence of diabetes, primary PCI, post-PCI thrombolysis in myocardial infarction flow of less than 3, multivessel disease, ischaemia time of less than $3 \mathrm{~h}$, time to first medical contact or first device placement of less than 120 min, ejection fraction of less than $30 \%$, Killip class greater than I, ST-segment resolution of greater than $70 \%$, use of aspiration thrombectomy catheters, left anterior descending as infarct-related artery, and need for staged procedure.

This trial is registered with ClinicalTrials.gov identifier, NCT00828087.

\section{Role of the funding source}

The funder of the study provided funding for independent data management and all statistical analyses by Cardialysis (Rotterdam, Netherlands) and had no role in the study design or the decision to submit for publication. The principal investigators had full access to the data in the study. The corresponding author had full responsibility for the decision to submit the report for publication.

\section{Results}

Between Dec 31, 2008, and May 15, 2010, 1504 patients with ST-elevation myocardial infarction for up to $48 \mathrm{~h}$ after the onset of symptoms were recruited; six withdrew consent after randomisation. 1498 patients were randomly assigned to receive either an EES $(\mathrm{n}=751)$ or a BMS $(\mathrm{n}=747)$. At 5 years, complete clinical follow-up was obtained for 731 patients treated with EES and 727 treated with BMS (97\% of both groups; figure 1). Baseline and procedural characteristics were similar between the two groups ${ }^{21}$ (appendix). Use of dual antiplatelet therapy beyond the 1-year prescription time was reduced similarly in both groups during the follow-up (appendix). At 5 years, 57 (9\%) of 622 participants in the BMS group and $64(10 \%)$ of 648 in the EES group were still on a dual antiplatelet regimen (appendix).

At the 5-year follow-up, the patient-oriented combined endpoint occurred in 159 (21\%) of 751 patients in the EES group and 192 (26\%) of 747 patients in the BMS group (hazard ratio [HR] $0 \cdot 80 ; 95 \%$ CI $0.65-0 \cdot 98 ; \mathrm{p}=0 \cdot 033$; table). This difference was mainly attributable to a significant reduction in the rate of all-cause death and a non-significant reduction in any revascularisation (table). 
The overall reduction in all-cause death was attributable to a non-significant reduction in cardiac and vascular deaths (absolute reduction 1\%) and a significant reduction in non-cardiovascular death (absolute reduction 2\%; table). The specific causes of noncardiovascular death are shown in the appendix. Most common causes of non-cardiac death included cancer and infection or sepsis. No significant differences were noted between the groups in the rate of any myocardial infarction. The device-oriented combined endpoint occurred in 88 (12\%) patients in the EES group and $113(15 \%)$ patients in the BMS group (HR 0.75, 95\% CI

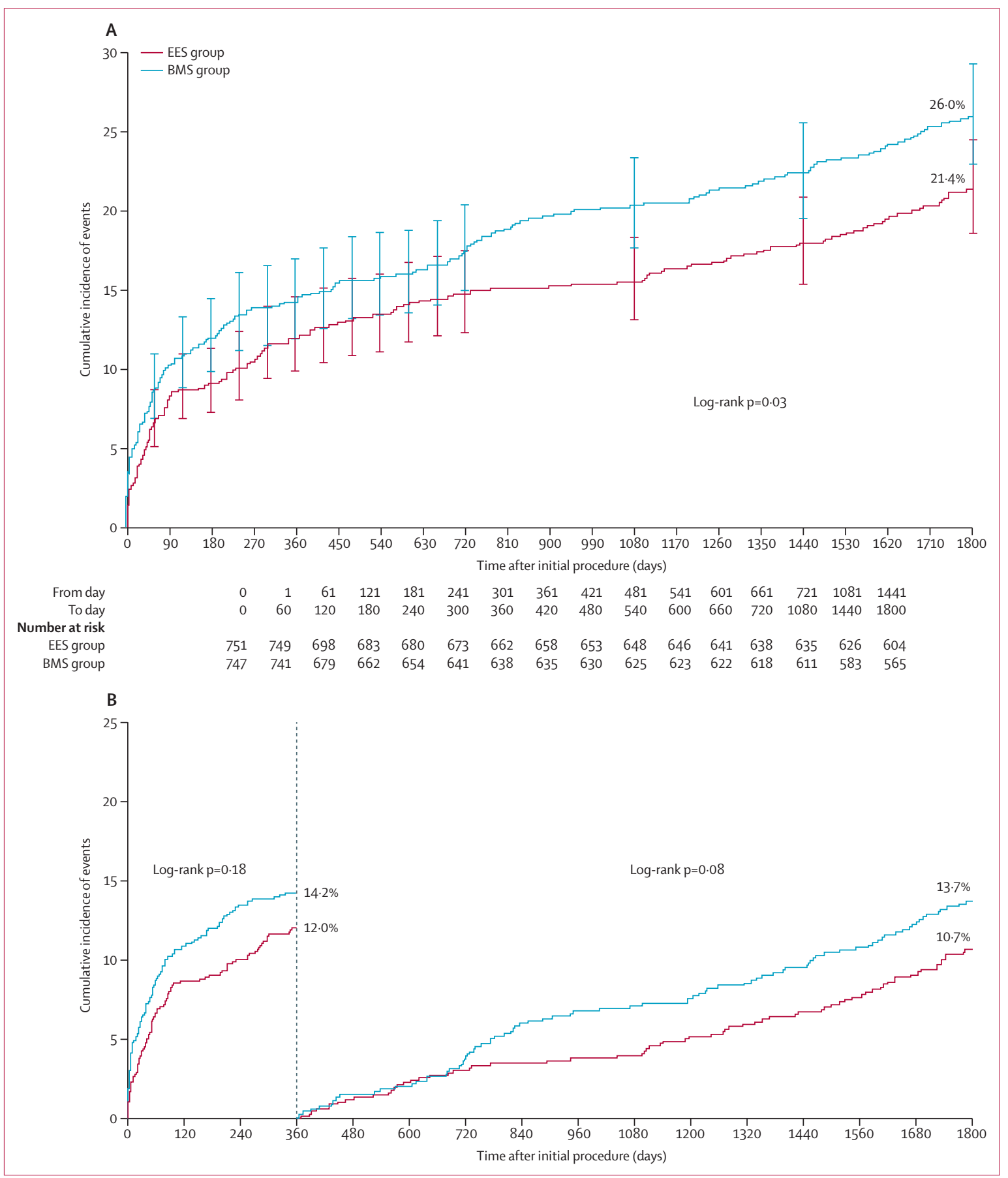

Figure 2: Time-to-event analysis of the patient-oriented endpoint of all-cause death, any myocardial infarction, or any revascularisation over 5 years (A) Kaplan-Meier analysis of cumulative 5-year incidence. (B) Landmark analyses for 0-1 year and 1-5years. Error bars indicate point-wise two-sided $95 \% \mathrm{Cl}$ with a complementary log-log transformation. SE was calculated with the Greenwood Formula. 


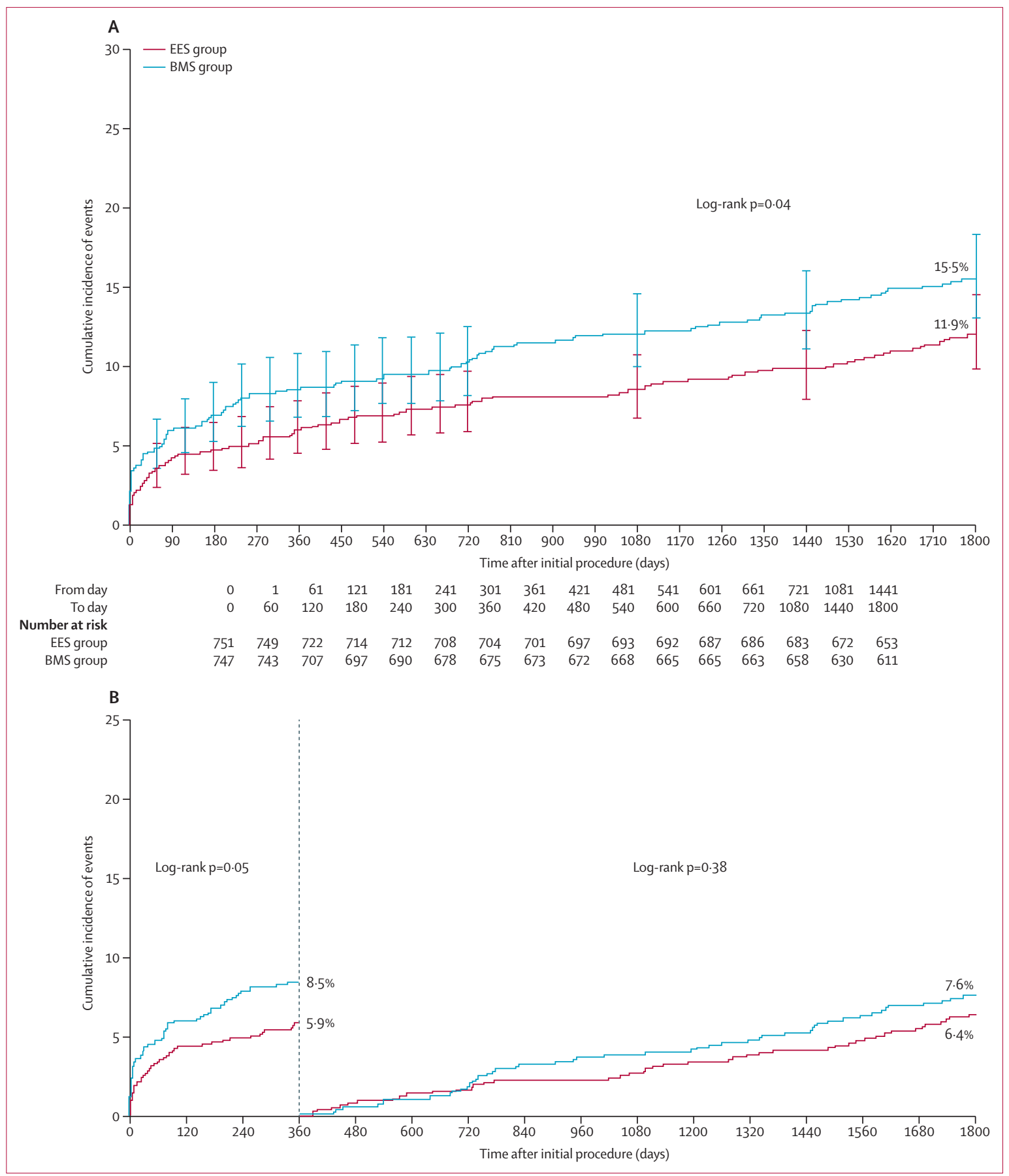

Figure 3: Time-to-event curves for the device-oriented endpoint of cardiac death, target vessel myocardial infarction, or target lesion revascularisation over 5 years

EES=everolimus-eluting stents. BMS=bare-metal stents. (A) Kaplan-Meier analysis of cumulative 5-year incidence. (B) Landmark analyses for 0-1 year and 1-5years. Error bars indicate point-wise 2-sided $95 \% \mathrm{Cl}$ with a complementary log-log transformation. SE was calculated with the Greenwood Formula.

0.57-0.99; $\mathrm{p}=0 \cdot 043 ;$ table). This difference was mainly attributable to a significant reduction in the rate of target lesion revascularisation (table). No differences between groups were noted in the rates of cardiac death and target vessel myocardial infarction (table).
From day 0, Kaplan-Meier curves began to diverge for the patient-oriented endpoint in favour of EES for up to 1 year, and later diverged again from year 2 to year 5 (figure 2A, B). A test for interaction between treatment effect and time (day 0 to 1 year and 1-5 years) was 


\begin{tabular}{|c|c|c|c|c|c|c|}
\hline & EES group & BMS group & $p$ value & Relative risk (95\% Cl) & & $p_{\text {interaction }}$ \\
\hline \multicolumn{7}{|l|}{ Sex } \\
\hline Male & 139/634 (22\%) & $151 / 610(25 \%)$ & 0.238 & $0.89(0.72-1.08)$ & $\rightarrow$ & \multirow[b]{2}{*}{0.140} \\
\hline Female & 20/117 (17\%) & $41 / 137(30 \%)$ & 0.017 & $0.57(0.36-0.92)$ & $\longrightarrow$ & \\
\hline \multicolumn{7}{|l|}{ Age (years) } \\
\hline$<75$ & 112/638 (18\%) & $132 / 615(21 \%)$ & 0.081 & $0.82(0.65-1.03)$ & $\rightarrow$ & \multirow[b]{2}{*}{0.631} \\
\hline$\geq 75$ & $47 / 113(42 \%)$ & $60 / 132(45 \%)$ & 0.544 & $0.92(0.69-1.22)$ & $\rightarrow$ & \\
\hline \multicolumn{7}{|l|}{ Diabetes } \\
\hline No & $114 / 613(19 \%)$ & $153 / 626(24 \%)$ & 0.012 & $0.76(0.61-0.94)$ & $\Rightarrow$ & \multirow[b]{2}{*}{0.245} \\
\hline Yes & $45 / 137(33 \%)$ & $39 / 121(32 \%)$ & 0.916 & $1.02(0.72-1.45)$ & $\rightarrow$ & \\
\hline \multicolumn{7}{|c|}{ Thrombectomy catheter } \\
\hline No & $60 / 256(23 \%)$ & $75 / 266(28 \%)$ & 0.215 & $0.83(0.62-1.11)$ & $\rightarrow$ & \multirow[b]{2}{*}{0.961} \\
\hline Yes & 99/495 (20\%) & $117 / 481(24 \%)$ & 0.104 & $0.82(0.65-1.04)$ & $\rightarrow$ & \\
\hline \multicolumn{7}{|c|}{ Ejection fraction } \\
\hline$<30 \%$ & $4 / 10(40 \%)$ & $3 / 5(60 \%)$ & 0.464 & $0.67(0.23-1.89)$ & - & \multirow{2}{*}{0.768} \\
\hline$\geq 30 \%$ & $109 / 531(21 \%)$ & $125 / 510(25 \%)$ & 0.124 & $0.84(0.67-1.05)$ & $\rightarrow$ & \\
\hline \multicolumn{7}{|l|}{ Primary PCI } \\
\hline Yes* & $133 / 630(21 \%)$ & $161 / 638(25 \%)$ & 0.082 & $0.84(0.68-1.02)$ & $\rightarrow$ & \multirow[b]{2}{*}{0.702} \\
\hline No & $26 / 121(21 \%)$ & $31 / 108(29 \%)$ & 0.207 & $0.75(0.48-1.18)$ & $\rightarrow-$ & \\
\hline \multicolumn{7}{|c|}{ Door to balloon (min) } \\
\hline$<120$ & $65 / 302(22 \%)$ & $70 / 280(25 \%)$ & 0.321 & $0.86(0.64-1.16)$ & $\rightarrow$ & \multirow[b]{2}{*}{0.926} \\
\hline$\geq 120$ & $80 / 356(22 \%)$ & $93 / 364(26 \%)$ & 0.334 & $0.88(0.68-1.14)$ & $\rightarrow$ & \\
\hline \multicolumn{7}{|c|}{ Ischaemia (min) } \\
\hline$<180$ & 46/199 (23\%) & $48 / 196(24 \%)$ & 0.748 & $0.94(0.66-1.34)$ & $\rightarrow$ & \multirow[b]{2}{*}{0.652} \\
\hline$\geq 180$ & $91 / 433(21 \%)$ & $103 / 413(25 \%)$ & 0.175 & $0.84(0.66-1.08)$ & $\rightarrow$ & \\
\hline \multicolumn{7}{|l|}{ Vessel disease } \\
\hline One & $130 / 649(20 \%)$ & $156 / 659(24 \%)$ & 0.111 & $0.85(0.69-1.04)$ & $\rightarrow-$ & \multirow[b]{2}{*}{0.446} \\
\hline Two or more & $28 / 100(28 \%)$ & $36 / 88(41 \%)$ & 0.062 & $0.68(0.46-1.02)$ & $\rightarrow-$ & \\
\hline \multicolumn{7}{|c|}{ Culprit lesion in LAD } \\
\hline No & $95 / 423(22 \%)$ & $113 / 439(26 \%)$ & 0.260 & $0.87(0.69-1.11)$ & $\rightarrow$ & \multirow[b]{2}{*}{0.530} \\
\hline Yes & $64 / 328(20 \%)$ & $79 / 308(26 \%)$ & 0.064 & $0.76(0.57-1.02)$ & $\rightarrow-$ & \\
\hline \multicolumn{7}{|c|}{ Post-procedure TIMI flow } \\
\hline$<3$ & $10 / 46(22 \%)$ & $18 / 44(41 \%)$ & 0.050 & $0.53(0.28-1.02)$ & 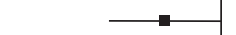 & \multirow[b]{2}{*}{0.237} \\
\hline 3 & 149/703 (21\%) & $172 / 700(25 \%)$ & 0.132 & $0.86(0.71-1.05)$ & $\rightarrow$ & \\
\hline \multicolumn{7}{|l|}{ ST resolution } \\
\hline$>70 \%$ & 78/414 (19\%) & $96 / 438(22 \%)$ & 0.265 & $0.86(0.66-1.12)$ & $\rightarrow-$ & \\
\hline$\leq 70 \%$ & $66 / 264(25 \%)$ & $74 / 236(31 \%)$ & 0.114 & $0.80(0.60-1.06)$ & $\rightarrow-$ & 0.741 \\
\hline Killip class on & & & & & & \\
\hline$>1$ & $21 / 80(26 \%)$ & $34 / 76(45 \%)$ & 0.016 & $0.59(0.38-0.91)$ & $\longrightarrow-$ & \\
\hline 1 & $138 / 669(21 \%)$ & $157 / 668(24 \%)$ & 0.205 & $0.88(0.72-1.07)$ & $\rightarrow$ & 0.181 \\
\hline Staged procec & & & & & & \\
\hline No & $121 / 625(19 \%)$ & $156 / 648(24 \%)$ & 0.042 & $0.80(0.65-0.99)$ & $\rightarrow$ & \\
\hline Yes & $35 / 123(28 \%)$ & $36 / 99(36 \%)$ & 0.209 & $0.78(0.53-1.15)$ & $\rightarrow$ & 0.918 \\
\hline Overall & $159 / 751(21 \%)$ & $192 / 747(26 \%)$ & 0.038 & $0.82(0.69-0.99)$ & $=-$ & \\
\hline & & & & & $\begin{array}{llllll} & & 1 & & 1 & 1 \\
1.0\end{array}$ & \\
\hline & & & & & Favours EES & \\
\hline
\end{tabular}

Figure 4: Subgroup analysis of the patient-oriented endpoint of all-cause death, any myocardial infarction, and any revascularisation at 5 years in the EES and BMS groups

Data are $\mathrm{n} / \mathrm{N}(\%)$, unless otherwise indicated. EES=everolimus-eluting stents. BMS=bare-metal stents. LAD=left anterior descending artery. $\mathrm{PCl}=$ percutaneous coronary intervention. TIMI=thrombolysis in myocardial infarction. *ST-elevation myocardial infarction for less than $12 \mathrm{~h}$.

negative $\left(\mathrm{p}_{\text {interaction }}=0.69\right.$ for the patient-oriented outcome and $\mathrm{p}_{\text {interaction }}=0.65$ for the device-oriented outcome). The same pattern was noted in the time-to-event curves for the device-oriented endpoint (figure 3A, B). The results for the patient-oriented (figure 4) and device-oriented endpoints (appendix) were consistent across the stratified analysis. Time-to-event curves for individual components of the patient-oriented and device-oriented endpoints are presented in the appendix. Of note, the difference in allcause death was evident beyond the 2 years of follow-up and the difference in target lesion revascularisation in the period between day 0 to 1 year.

At 5 years, the EES and BMS groups had similar rates of definite stent thrombosis ( $2 \%$ vs $2 \%$; HR $0.65,95 \%$ CI 
$0 \cdot 31-1 \cdot 36 ; \mathrm{p}=0 \cdot 25)$ and of definite or probable stent thrombosis ( $2 \%$ vs $3 \%$; $0.64,0.33-1 \cdot 23 ; \mathrm{p}=0 \cdot 18$; table). From day 0, Kaplan-Meier curves began to diverge for definite or probable stent thrombosis in favour of EES for up to 30 days, and remained parallel thereafter (appendix). Interaction between day 0 to 1 year and year 1 to year 5 was significant $\left(\mathrm{p}_{\text {interaction }}=0 \cdot 02\right)$. The combined endpoints of allcause death or definite $(76$ [10\%] of 751 patients vs 105 [14\%] of 747 patients; HR $1 \cdot 44$, 95\% CI 1.05-1.97, $\mathrm{p}=0 \cdot 024$ ) and all-cause death or definite or probable stent thrombosis showed significant reductions also favouring the use of EES (76 [10\%] vs 104 [14\%]; 1.45, 1.06-1.99, $\mathrm{p}=0 \cdot 020)$.

\section{Discussion}

In patients with ST-elevation myocardial infarction requiring emergency primary PCI, durable polymerbased EES was superior to BMS in the patient-oriented and in the device-oriented endpoints. The benefits of EES were driven by reductions in the rates of all-cause death, non-cardiac death, and target lesion revascularisation. The results of this landmark analysis showed the absence of very late ( $>1$ year) hazards and a benefit of EES compared with BMS over time.

The use of these endpoints in DES trials has been strongly recommended by the ARC group ${ }^{23}$ and yet the patient-oriented endpoint was not selected as a primary endpoint in reported studies of stents. The global patient-oriented endpoint was specifically focused on the patients' outcomes rather than the specific effect of a study stent. It has the potential to show the complex interplay between device performance, revascularisation strategy, concomitant antithrombotic regimen, secondary prevention, residual left ventricle function, and other key descriptors for patients (eg, diabetes mellitus and renal function)

An improved global perspective is of utmost importance because outcomes in the context of ST-elevation myocardial infarction are multifactorial and often not directly related to the stent implanted at the index procedure. Differences in the patient-oriented endpoint might accrue over a longer period than previously thought, as shown by the results in this study. We found no differences in this endpoint for up to 2 years,,$^{21,22}$ but significant differences were noted at 5 years. Furthermore, concomitant reporting of the device-oriented endpoint, as recommended by the $\mathrm{ARC}$, might help to define the true contribution of the stent.

The superiority of the EES over BMS was slight overall ( $5 \%$ absolute reduction in the rate of the patient-oriented endpoint) and it was mainly attributable to reduced rate of all-cause death and revascularisation. The reduction in all-cause and non-cardiac mortality rates cannot be directly explained. According to the results of landmark analyses, there was no interaction between treatment effect and time. The benefit of EES occurred immediately after implantation and up to 1 year and also at long-term follow-up beyond 2 years (figures 2 and 3). We could hypothesise that the actual reduction in early stent thrombosis and repeated revascularisation rates might have improved preservation of the left ventricle ejection fraction, leading to improved long-term outcomes and reduced need for readmission to hospital as potential cause of further complications including infections or sepsis, which seemed to be the second major cause of non-cardiac death in our population (appendix). Therefore, this finding should be further investigated and confirmed in trials specifically focused on this endpoint.

Our results show the extended benefit of EES over BMS in terms of target lesion and target vessel revascularisation in patients with ST-elevation myocardial infarction for up to 5-years of follow-up. This finding dispels any concern about a restenosis late catch-up phenomenon, as initially suggested for EES based on the 2-year imaging outcome data from SPIRIT II. ${ }^{25}$

Very late hazards such as stent thrombosis or target vessel myocardial infarction have not been reported in the extended clinical follow-up. In our trial, stent thrombosis remained at a low level and was lower at 5 years in patients who received EES (2\%). Of note, the benefit in stent thrombosis occurred mainly during the early phase (up to 30 days) with no thrombotic late catch-up phenomenon thereafter $\left(\mathrm{p}_{\text {interaction }}=0 \cdot 02\right.$; appendix $)$. The overall reduction in the patient-oriented endpoint was consistent across all prespecified subgroups (figure 4). Stenting did not seem to have an effect in people with diabetes and the interaction between diabetes and treatment effect was not significant.

The only differences between the two stent platforms used in this trial were the presence or absence of drug delivery and EES had a durable polymer and co-polymer composed of vinylidene fluoride and hexafluoropropylene monomers, which might have induced healthy endothelialisation of the stent and some thromboresistance and haemocompatibility, as suggested by the results of laboratory tests. ${ }^{26}$ This haemocompatibility could be especially relevant in the context of ST-elevation myocardial infarction, in which the eventual dissolution of the thrombus behind the struts might lead to a high incidence of late-acquired malapposition..$^{27}$ Furthermore, thrombus-containing plaques, commonly found in patients with ST-elevation myocardial infarction, have been the model of delayed arterial healing after DES implantation. Specifically, the mean rate of uncovered stents seemed to be as high as $49 \%$ in culprit lesions from patients with ST-elevation myocardial infarction, compared with $9 \%$ in stable plaques after sirolimuseluting stent implantation. ${ }^{11}$ In this clinical context, long-term presence of a durable polymer has been proposed as a point of origin for a chronic inflammatory response that might delay the healing process. ${ }^{12}$ Therefore, research in this field has been redirected toward biodegradable polymer-based metallic DES, polymer-free DES, or completely bioresorbable scaffolds. ${ }^{28-30}$ Although these pathological findings were noted after implantation of first-generation DES, the use of EES has provided 
reassuring data in imaging studies in animals and people ${ }^{31-33}$ that have been confirmed in a network meta-analysis of ST-elevation myocardial infarction. ${ }^{34}$ However, this meta-analysis was limited by the availability of only two trials specifically designed for patients with ST-elevation myocardial infarction (the EXAMINATION trial $^{21}$ and the XAMI trial ${ }^{35}$ of the comparison of EES vs first-generation sirolimus-eluting stents) and by the shorter follow-up (1 year and 2 years). Our 5-year follow-up findings provide reassurance about safety of using a second-generation durable polymer stent.

Because our study was single-blind, bias cannot be completely ruled out. Results of this long-term follow-up have to be regarded as exploratory because outcomes were not significant at the time of the primary endpoint analysis (1 year). ${ }^{21}$ Specifically, the benefit in reduction of the mortality rate with the use of EES should be thought of as hypothesis-generating. Further assessment in a properly powered trial is needed with an endpoint of reducing the mortality rate.

In this trial, patients with ST-elevation myocardial infarction were treated with aspirin and 1 year of clopidogrel as dual antiplatelet therapy. The potential role of ticagrelor or prasugrel in further prevention of events (eg, stent thrombosis, recurrent myocardial infarction, or mortality) in this context was not assessed because these treatments were not available at the time of recruitment. Thus, the potential extended benefit of new antiplatelet agents beyond 1 year of follow-up ${ }^{36}$ has not been addressed in our study.

Although trial participants might adequately represent the real-world population admitted with ST-elevation myocardial infarction, because the all-comers design allowed the inclusion of most patients $(70 \%)$ presenting at our institutions, ${ }^{21}$ there are still some patients to whom the reported results do not apply (excluded population). Further long-term research in the excluded populations is needed.

Our results lay the foundation for future developments in stent technologies and should be taken as a point of reference for the assessment of new bioresorbable polymer-based metallic stents or bioresorbable scaffolds in this clinical context.

\section{Contributors}

MS and PWS contributed to the design and execution of the trial. MS drafted the report, which was critically revised by MV, SB, AC, PJ-Q, and PWS. AC, AI, SB, AS, PJ-Q, VM, MV, GC, MT, PdH, AB, and NV contributed to the execution of the trial. BB and G-AvE did the statistical analysis. All authors approved the final report.

\section{Declaration of interests}

MS has received consultancy and speakers' fees from Abbott Vascular and Medtronic. SB has received speakers' fees from Abbott Vascular and St Jude Medical. MV has received an honorarium as a public speaker for Terumo, the Medicines Company, Medtronic, Iroko, Merck, Abbott, Ely Lilly, AstraZeneca, Cordis, Carbostent and Implantable Devices, and Bayer. BB and G-AvE are employees of Cardialysis. The other authors declare no competing interests.

\section{Acknowledgments}

This trial was partly funded by an unrestricted grant from the promoter Abbott Vascular to the Spanish Heart Foundation.
References

1 Windecker S, Kolh P, Alfonso F, et al. 2014 ESC/EACTS Guidelines on myocardial revascularization: The Task Force on Myocardial Revascularization of the European Society of Cardiology (ESC) and the European Association for Cardio-Thoracic Surgery (EACTS). Developed with the special contribution of the European Association of Percutaneous Cardiovascular Interventions (EAPCI). Eur Heart J 2014; 35: 2541-619.

2 Steg PG, Fox KA, Eagle KA, et al. Mortality following placement of drug-eluting and bare-metal stents for ST-segment elevation acute myocardial infarction in the Global Registry of Acute Coronary Events. Eur Heart J 2009; 30: 321-29.

3 Spaulding C, Henry P, Teiger E, et al. Sirolimus-eluting versus uncoated stents in acute myocardial infarction. N Engl J Med 2006; 355: 1093-104.

4 Valgimigli M, Campo G, Arcozzi C, et al. Two-year clinical follow-up after sirolimus-eluting versus bare-metal stent implantation assisted by systematic glycoprotein IIb/IIIa Inhibitor Infusion in patients with myocardial infarction: results from the STRATEGY study. J Am Coll Cardiol 2007; 50: 138-45.

5 Stone GW, Witzenbichler B, Guagliumi G, et al, on behalf of the HORIZONS-AMI Trial Investigators. Heparin plus a glycoprotein IIb/IIIa inhibitor versus bivalirudin monotherapy and paclitaxel-eluting stents versus bare-metal stents in acute myocardial infarction (HORIZONS-AMI): final 3-year results from a multicentre, randomised controlled trial. Lancet 2011; 377: 2193-204.

6 Kastrati A, Dibra A, Spaulding C, et al. Meta-analysis of randomised trials on drug-eluting stents vs bare-metal stents in patients with acute myocardial infarction. Eur Heart J 2007; 28: 270613.

7 Stettler C, Wandel S, Allemann S, et al. Outcomes associated with drug-eluting and bare-metal stents: a collaborative network meta-analysis. Lancet 2007; 370: 937-48.

8 Wenaweser P, Daemen J, Zwahlen M, et al. Incidence and correlates of drug-eluting stent thrombosis in routine clinical practice. 4-year results from a large 2-institutional cohort study. J Am Coll Cardiol 2008; 52: 1134-40.

9 Kastrati A, Mehilli J, Pache J, et al. Analysis of 14 trials comparing sirolimus-eluting stents with bare-metal stents. N Engl J Med 2007; 356: 1030-39.

10 Stone GW, Moses JW, Ellis SG, et al. Safety and efficacy of sirolimus- and paclitaxel-eluting coronary stents. N Engl J Med 2007; 356: 998-1008.

11 Nakazawa G, Finn AV, Joner M, et al. Delayed arterial healing and increased late stent thrombosis at culprit sites after drug-eluting stent placement for acute myocardial infarction patients: an autopsy study. Circulation 2008; 118: 1138-45.

12 Finn AV, Nakazawa G, Joner M, et al. Vascular responses to drug eluting stents: importance of delayed healing. Arterioscler Thromb Vasc Biol 2007; 27: 1500-10.

13 Cook S, Ladich E, Nakazawa G, et al. Correlation of intravascular ultrasound findings with histopathological analysis of thrombus aspirates in patients with very late drug-eluting stent thrombosis. Circulation 2009; 120: 391-99.

14 Joner M, Finn AV, Farb A, et al. Pathology of drug-eluting stents in humans: delayed healing and late thrombotic risk. J Am Coll Cardiol 2006; 48: 193-202.

15 Wilson GJ, Nakazawa G, Schwartz RS, et al. Comparison of inflammatory response after implantation of sirolimus- and paclitaxel-eluting stents in porcine coronary arteries. Circulation 2009; 120: 141-49.

16 Park SJ, Kang SJ, Virmani R, Nakano M, Ueda Y. In-stent neoatherosclerosis: a final common pathway of late stent failure. J Am Coll Cardiol 2012; 59: 2051-57.

17 Yonetsu T, Kim JS, Kato K, et al. Comparison of incidence and time course of neoatherosclerosis between bare metal stents and drug-eluting stents using optical coherence tomography. Am J Cardiol 2012; 110: 933-39.

18 Valgimigli M, Sabaté M, Kaiser C, et al. Effects of cobalt-chromium everolimus eluting stents or bare metal stent on fatal and non-fatal cardiovascular events: patient level meta-analysis. BMJ 2014; 349: g6427.

19 Baber U, Mehran R, Sharma SK, et al. Impact of the everolimuseluting stent on stent thrombosis: a meta-analysis of 13 randomized trials. J Am Coll Cardiol 2011; 58: 1569-77. 
20 Sabaté M, Cequier A, Iniguez A, et al. Rationale and design of the EXAMINATION trial: a randomised comparison between everolimus-eluting stents and cobalt-chromium bare-metal stents in ST-elevation myocardial infarction. EuroIntervention 2011; 7: 977-84.

21 Sabaté M, Cequier A, Iñiguez A, et al. Everolimus-eluting stent versus bare-metal stent in ST-segment elevation myocardial infarction (EXAMINATION): 1 year results of a randomised controlled trial. Lancet 2012; 380: 1482-90.

22 Sabaté M, Brugaletta $\mathrm{S}$, Cequier A, et al. The EXAMINATION trial (Everolimus-Eluting Stents Versus Bare-Metal Stents in ST-Segment Elevation Myocardial Infarction): 2-year results from a multicenter randomised controlled trial. JACC Cardiovasc Interv 2014; 7: 64-71.

23 Cutlip DE, Windecker S, Mehran R, et al. Clinical end points in coronary stent trials: a case for standardized definitions. Circulation 2007; 115: 2344-51.

24 Vranckx P, Cutlip DE, Mehran R, et al. Myocardial infarction adjudication in contemporary all-comer stent trials: balancing sensitivity and specificity. Addendum to the historical MI definitions used in stent studies. EuroIntervention 2010; 5: 871-74.

25 Serruys PW, Ruygrok P, Neuzner J, et al. A randomised comparison of an everolimus-eluting coronary stent with a paclitaxel-eluting coronary stent: the SPIRIT II trial. EuroIntervention 2006; 2: 286-94.

26 Kolandaivelu K, Swaminathan R, Gibson WJ, et al. Stent thrombogenicity early in high-risk interventional settings is driven by stent design and deployment and protected by polymer-drug coatings. Circulation 2011; 123: 1400-09.

27 Gonzalo N, Barlis P, Serruys PW, et al. Incomplete stent apposition and delayed tissue coverage are more frequent in drug-eluting stents implanted during primary percutaneous coronary intervention for ST-segment elevation myocardial infarction than in drug-eluting stents implanted for stable/unstable angina: insights from optical coherence tomography. JACC Cardiovasc Interv 2009; 2: 445-52.

28 Puricel S, Arroyo D, Corpataux N, et al. Comparison of everolimusand biolimus-eluting coronary stents with everolimus-eluting bioresorbable vascular scaffolds. J Am Coll Cardiol 2015; 65: 791-801.
29 Gomez-Lara J, Brugaletta S, Farooq V, et al. Head-to-head comparison of the neointimal response between metallic and bioresorbable everolimus-eluting scaffolds using optical coherence tomography. JACC Cardiovasc Interv 2011; 4: 1271-80.

30 Tada N, Virmani R, Grant G, et al. Polymer-free biolimus a9-coated stent demonstrates more sustained intimal inhibition, improved healing, and reduced inflammation compared with a polymer-coated sirolimus-eluting cypher stent in a porcine model. Circ Cardiovasc Interv 2010; 3: 174-83.

31 Nakazawa G, Shinke T, Ijichi T, et al. Comparison of vascular response between durable and biodegradable polymer-based drug-eluting stents in a porcine coronary artery model. EuroIntervention 2014; 10: 717-23.

32 Takano M, Murakami D, Yamamoto M, et al. Six-month follow-up evaluation for everolimus-eluting stents by intracoronary optical coherence tomography: comparison with paclitaxel-eluting stents. Int J Cardiol 2013; 166: 181-86.

33 Mizoguchi T, Sawada T, Shinke T, et al. Detailed comparison of intra-stent conditions 12 months after implantation of everolimus-eluting stents in patients with ST-segment elevation myocardial infarction or stable angina pectoris. Int J Cardiol 2014; 171: 224-30.

34 Palmerini T, Biondi-Zoccai G, Della Riva D, et al. Clinical outcomes with drug-eluting and bare-metal stents in patients with ST-segment elevation myocardial infarction: evidence from a comprehensive network meta-analysis. J Am Coll Cardiol 2013; 62: 496-504.

35 Hofma SH, Brouwer J, Velders MA, et al. Second-generation everolimus-eluting stents versus first-generation sirolimus-eluting stents in acute myocardial infarction. 1-year results of the randomised XAMI (XienceV stent vs. Cypher stent in primary PCI for Acute Myocardial Infarction) trial. J Am Coll Cardiol 2012; 60: 381-87.

36 Bonaca MP, Bhatt DL, Cohen M, et al, PEGASUS-TIMI 54 Steering Committee and Investigators. Long-term use of ticagrelor in patients with prior myocardial infarction. $N$ Engl J Med 2015; 372: $1791-800$. 